MIRA DE ORDUÑA Y GIL, José María Universidad Cardenal Herrera. CEU

@jmira@uchceu.es

MONFORT PRADES, Juan Manuel Universidad Cardenal Herrera. CEU

\title{
La víctima del bullying como chivo expiatorio. Casos judiciales
}

\author{
The victim of bullying as an sacapegoat. Judicial cases
}

\begin{abstract}
Partimos del interés por explorar algunas aplicaciones de la teoría girardiana a problemas de suma actualidad. Centraremos nuestro análisis en la violencia escolar, y más en concreto en los casos de bullying: aunque todos los casos de bullying son ejemplos de violencia escolar, no toda violencia escolar tiene por qué ser bullying, ya que una de sus características de este fenómeno social es que requiere de una habitualidad que no se da en el resto de la violencia escolar. Partimos de la hipótesis de que el bullying encierra en muchos casos (si no siempre) procesos de violencia mimética que desembocan en un chivo expiatorio, tal como ha sido descrito en las obras de Girard. Para verificar la hipótesis, dividiremos nuestra exposición en tres secciones bien delimitadas. En primer lugar, recordaremos los pasos en los que Girard divide los procesos de violencia mimética, victimización y condena del chivo expiatorio, con el consecuente aplacamiento de la violencia. En segundo lugar, intentaremos descubrir los pasos indicados por Girard en algunos casos de bullying real, basándonos en sentencias judiciales, puesto que dichas sentencias son un documento privilegiado para acceder a los elementos esenciales del problema. En tercer lugar, proponemos unas directrices para prevenir o afrontar los casos de acoso escolar basándonos en los análisis de Girard.
\end{abstract}

PALABRAS CLAVE: chivo expiatorio, bullying, educación, Girard, jurisprudencia.

The starting point of this paper is the interest in exploring some applications of the girardian philosophy to nowadays issues. In particular, we would like to focus our analysis in school violence, and more specifically, in those cases known as bullying (since all cases of bullying are examples of school violence, but not all school violence could be labelled as bullying indeed). The suggested hypothesis is that bullying, in many cases (if not all), is linked with a «mimetic violence process» as it has been described in Girard's research. To verify the hypothesis, we will divide our proposal into three well-defined sections. Firstly, the 
steps in which Girard describes the processes of mimetic violence will be displayed, that is to say: victimization and condemnation of the scapegoat, with the consequent violence decrease. Secondly, we will try to discover, in some cases of real bullying, all the keys highlighted by Girard, taking into account legal sentences (since these sentences are extraordinary documents to access the most relevant elements of the problem). Thirdly, we would like to point out Girard's solution to the processes of mimetic violence, and, finally, we try to offer a way to understand and solve nowadays cases of violence in classroom.

KEY WORDS: scapegoat, bullying, education, Girard, jurisprudence.

\section{INTRODUCCIÓN}

Estudios recientes han llegado a afirmar que el acoso escolar afecta a un $19 \%$ de los estudiantes en todo el mundo; en otras palabras, uno de cada cinco estudiantes sufre bullying a nivel global (OECD, 2015; Oñate y Piñuel, 2007; Ballesteros, 2017). El informe de la OCDE sobre bienestar escolar ha resultado altamente preocupante para el mundo educativo, lo que está provocando que los análisis sobre este fenómeno social se multipliquen y se intensifiquen. En este contexto nos proponemos llevar a cabo una aproximación al problema del acoso escolar desde la filosofía de René Girard, especialmente desde sus importantes conceptos de violencia mimética y chivo expiatorio, ambos centrales en su pensamiento.

Nuestro punto de partida será la concepción del aula como un microcosmos (Vilarrasa, 2008, pp. 59-60), como un pequeño espacio donde pueden analizarse sucesos, normas o costumbres que superan las fronteras del grupo y que son reflejo o consecuencia de fenómenos que afectan a toda la humanidad. Este tipo de análisis ha sido puesto en marcha por otros antropólogos o sociólogos (Slater, 1966), entre los que podrían destacarse las teorías del Mary Douglas sobre la concepción del cuerpo humano como un microcosmos para comprender los fenómenos relacionados con la pureza ritual:

The physical body can have universal meaning only as a system which responds to the social system, expressing it as a system. What it symbolizes naturally is the relation of parts of an organism to the whole. Natural symbols can express the relation of an individual to his society at that general systemic level. (Douglas, 1978, p. 112).

La violencia en la sociedad es el gran tema de la filosofía de Girard y para comprenderla y afrontarla desarrolla sus teorías filosóficas. Al hablar de la violencia como un proceso que crece en intensidad y cantidad, la presenta como:

... un torbellino en cuyo seno las violencias más violentas se congregan y confunden. Hay violencias familiares y escolares, esas de las que se hacen culpables esos adolescentes que masacran a sus camaradas en las escuelas americanas, $y$ hay violencias visibles por el mundo entero, el terrorismo sin límites y sin fronteras. Este último se entrega a una verdadera guerra de exterminio sobre poblaciones civiles. Parece como si nos dirigiéramos hacia una cita planetaria de toda la humanidad con su propia violencia. (Girard, 2006, p. 16). 
En estas palabras de Girard se atisban tres violencias contemporáneas: el terrorismo, la violencia de género y la violencia en la educación, tres grandes ámbitos preocupantes que merecen un continuo trabajo de profundización y análisis.

La teoría de la violencia mimética que Girard comenzó a exponer en Mentira romántica y verdad novelesca (2006) ha sido ya el punto de partida para explicar otros problemas sociales, de forma que este trabajo viene a profundizar algunas propuestas ya existentes. El mismo René Girard intentó dar explicación, por ejemplo, de la anorexia en su ensayo La anorexia y el deseo mimético (2009); y otros autores han utilizado dicha teoría también para dar razón, por ejemplo, de las innumerables migraciones (Burbano, 2010, pp. 159 y ss.) que hoy sacuden el panorama social.

En el análisis que se presenta quisiéramos llevar la teoría del deseo mimético al terreno del aula y sus problemas. Este tipo de análisis ha sido en parte propuesto por otros investigadores que conviene recordar para marcar distancia entre esta investigación y las ya realizadas. Pueden destacarse tres trabajos que en una medida u otra han intentado aplicar la teoría de Girard al tema de la educación y a los conflictos que se desatan en los centros escolares, todos publicados en el volumen que la revista Anthropos dedicó a Girard bajo el título René Girard. Deseo mimético y estructura antropológica (2006).

El primero lleva por título «El respeto a los niños, una vía hacia la autonomía al margen del mimetismo de la violencia». La propuesta de este trabajo es revisar cómo se educa a los niños, especialmente qué tipo de educación brindan las instituciones educativas para prevenir la violencia mimética. Para el autor la violencia que sufre un ser humano en la niñez se puede convertir en un veneno que intoxica el resto de su existencia, por lo que resulta absolutamente necesario denunciarla y evitarla: «La violencia sufrida en la infancia enseña también al niño a someterse, no ya a la ley, sino a la violencia y a las personalidades violentas. Cuanto más sufre la violencia un niño sin poderla evitar, porque todo su entorno la considera normal y benéfica, más capaz es de dejarse adoctrinar y someter por tal o cual líder político violento que reproduce el comportamiento parental» (Maurel, 2006, p. 144). Aunque habría que estar atentos a no caer en determinismos sociales.

El segundo texto es «Harry Potter: de la crisis de las diferencias a la diferenciación de las identidades y de las disciplinas (una aproximación antropológica de la violencia en la escuela)» (Biaglioli y Martínez, 2006, pp. 152 y ss.). La tesis del trabajo es que en Harry Potter se encuentran indicios suficientes, al alcance de los niños, para identificar el ciclo antropológico de la violencia y lo sagrado. En definitiva es una forma de afirmar que existen libros que permiten prevenir la violencia en el mundo educativo y que algunos de ellos son muy atractivos para los niños. Es una propuesta de filosofía girardiana de la educación y un interesante camino abierto para explorar.

Por último, y mucho más próximo al tema que se tratará a continuación nos encontramos con: «Aproximación antropológica a la violencia en la escuela y en el deporte», donde se afirma a propósito del concepto de chivo expiatorio que «a través de los análisis teóricos críticos, podemos actualizarlo y reconstruirlo pues aflora en las condiciones interpersonales, las situaciones institucionales, los mitos y los ritos, la literatura y otras instituciones [...]. Se trata de estar atentos a las formas modernas o posmodernas que adquiere el chivo expiatorio (acoso, fenómeno victimario, etc.)» (Martínez, 2006, p. 171). Si bien este trabajo no se adentra en el caso del acoso escolar, podemos decir que se asoma a su problemática y puede servirnos de punto de partida para desarrollar un análisis de mayor calado. 
Cabría tener presentes además los análisis de A. Barahona, reconocido experto en Girard, en su artículo sobre la violencia escolar (Barahona, 2001, pp. 37 y ss.). Iñaki Piñuel ha aplicado las teorías de Girard al fenómeno del mobbing (Piñuel, 2001, p. 101). Más recientemente, junto con O. Cortijo, ha hecho referencia al fenómeno aplicado al bullying (Piñuel y Cortijo, 2016, p. 16). La novedad que se pretende aportar aquí consistiría más bien en un cambio de acento al considerar al chivo expiatorio no como un elemento más del bullying, sino como la clave de comprensión del fenómeno de la violencia escolar y su conversión en violencia habitual sobre un sujeto. Además, también es novedoso que el análisis se base en hechos considerados probados por sentencias judiciales.

\section{Violencia mimética y el chivo expiatorio según René Girard}

Lo que algunos psicólogos habían indicado como un fenómeno concomitante del bullying, el chivo expiatorio, parece que puede convertirse en la clave de bóveda para la comprensión del problema en su totalidad. Pero no podemos saber si esto ocurre o no en los casos reales si antes no tenemos una idea clara y distinta del fenómeno del chivo expiatorio, descrito en los términos en que Girard lo hace.

\subsection{Sentido bíblico y sentido coloquial del término}

Girard afirma en repetidas ocasiones que hay un uso técnico de la palabra chivo expiatorio y hay un uso coloquial del mismo. Aunque Girard suele usar este término en su sentido más trivial, es necesario recordar cuáles son sus claves desde el punto de vista histórico-cultural. El uso técnico del término tiene que ver con la teología bíblica y el estudio del judaísmo (Eichrodt, 1975, pp. 129 y ss.; De Vaux, 1976, pp. 636 y ss.), y consiste en la selección de dos machos cabríos en el día de la expiación, uno para que fuera sacrificado con el fin de expiar los pecados del pueblo (de ahí la expresión chivo expiatorio), y el otro para ser cargado simbólicamente con los pecados del pueblo y ser expulsado al desierto (de ahí la expresión inglesa scapegoat). Sin embargo, algunos autores afirman que el sentido que Girard atribuye al término no tiene que ver con el bíblico:

A esta víctima elegida y sacrificada para bien de todos la denomina $R$. Girard «el chivo expiatorio». No tiene ninguna connotación bíblica. Nuestro autor lo entiende en el sentido más popular y trivial: como un mecanismo espontáneo y psicológicamente inconsciente que señala a alguien, falsamente acusado, y lo sacrifica. (Mardones, 2006, p. 60).

El sentido coloquial de la expresión reúne los dos chivos empleados en la conmemoración judía, y los une en un solo sujeto, que adquiere las connotaciones de sacrificio, expiación, carga de la culpa común y expulsión de la comunidad. Así que empleamos la expresión chivo expiatorio (o cabeza de turco) cuando nos encontramos ante alguien al que se le ha cargado con culpas de las que él no es responsable. Volviendo de nuevo al uso coloquial del lenguaje, 
alguien tiene que pagar los platos o los vidrios rotos, pagar el pato; alguien tiene que cargar con el muerto o con el mochuelo. $Y$ es sobre este sentido coloquial sobre el que se detiene la reflexión girardiana.

\subsection{La violencia mimética}

Según Girard, la violencia comienza cuando deseo lo que tiene el otro. En el origen serían la tierra, la mujer o el alimento (Girard, 1996, p. 25; Moreno, 2013, p. 196); en un instituto de secundaria, entre adolescentes, puede ser una ropa de marca, las buenas notas o el reconocimiento de los demás. La teoría del deseo mimético de Girard muestra que los deseos, lejos de ser innatos o socialmente impuestos, siempre nacen de la imitación del deseo del otro: siempre deseo a través de un tercero. Deseamos lo que desea el otro porque el otro lo desea, y al otro se le acrecienta el deseo cuando me ve deseando lo mismo que él. Cuando el otro deja de desearlo dejo yo también de tener interés por ello. No hacen falta estudios empíricos para convencerse de la verdad de esta experiencia tan cotidiana y tan evidente en los niños, que aún no son capaces de camuflar su mimetismo bajo una falsa pretensión de autonomía (García-Durán, 2012, pp. 71 y ss.).

Girard explica por qué las novelas han sido capaces de ver y mostrar este mecanismo básico de la vida en común, a diferencia de la filosofía: porque la novela representa la vida tal como es, mientras que la filosofía se preocupa más de abstraer (Girard, 1985, 1995). El proceso de mimetismo viene representado por un triángulo mimético: por un lado está el objeto de deseo, por otro estoy yo que deseo ese objeto, y por otro está el mediador del deseo: el otro a través del cual y por el cual yo he deseado el objeto. En palabras de Girard:

Los celos y la envidia suponen una triple presencia:presencia del objeto, presencia del sujeto, presencia de aquel a quien se envidia. Así pues, ambos defectos son triangulares: en cualquier caso, nunca percibimos un modelo en quien inspira los celos porque siempre adoptamos sobre los celos el punto de vista del propio celoso. Al igual que todas las víctimas de la mediación interna, el celoso se persuade fácilmente de que su deseo es espontáneo; es decir, que está arraigado en el objeto y únicamente en este objeto. Por consiguiente, el celoso sostiene siempre que su deseo ha precedido a la intervención del mediador. Nos lo presenta como a un intruso, un estorbo, un terzo incommodo que acude a interrumpir un delicioso têteà-tête. (Girard, 1985, p. 18).

El mediador del deseo en el fondo me estorba, porque poseyendo él el objeto no lo poseo yo; y si lo poseyéramos los dos, entonces seríamos iguales a ese respecto, dejándome igualmente insatisfecho.

Comenzamos a vislumbrar el problema: deseando lo que desea el otro, deseo ser el otro; me estoy homologando al otro. Si yo quiero las notas que tiene el otro y que lo diferencian del resto, no me doy cuenta de que al tener dichas notas sería igual que el otro y entonces tampoco me diferenciaría en nada, sobre todo si se da el caso de que todos obtienen el objeto 
deseado: notas elevadas. La paradoja del deseo mimético es que cuanto más intentamos todos diferenciarnos de la masa siguiendo el ejemplo de los que ya se diferencian por algo, más nos homologamos entre nosotros porque vamos consiguiendo los objetos deseados, que una vez conseguidos por todos no diferencian sino que homologan.

Situémonos en la piel de un alumno adolescente, dentro de un aula. Al ser adolescente quiere diferenciarse de un modo como aún no había sentido antes (lo cual explicaría en parte por qué el fenómeno del bullying se da a ciertas edades y no antes); el adolescente no se da cuenta de que diferenciándose, en el fondo, se homologa al resto y entonces se convierte en masa. El caso es bien patente en las tribus urbanas. ¿Qué marca la conducta, las pautas de pensamiento, etc., de un adolescente en su instituto? Lo que ve desear a los otros que están a su mismo nivel (porque, evidentemente, los objetos de deseo de un claustro profesoral varían respecto de los objetos de deseo de los alumnos).

Todo esto nos conduce a una situación de violencia larvada, de malestar, de homologación en una masa anónima a pesar de que me esfuerzo por ser diferente.

\subsection{Selección de la víctima y efecto bola de nieve}

Esta situación de violencia larvada, en la que el otro supone un obstáculo para la consecución de mi deseo (a pesar de que mi deseo viene precisamente mediado a través del otro) no puede durar mucho, puesto que nos conduce a un bellum omnium contra omnes. Así que, sin poder determinar muy bien por qué, aparece alguien que va a cumplir el papel de víctima. Es el que va a atraer la violencia de la comunidad, de la clase, del grupo humano con el cual se convive. En ocasiones se podrá determinar con precisión cuál fue la razón por la que se inicia la violencia concentrada contra uno (un supuesto desprecio, un objeto de marca deseado, etc.), en otras no resultará tan fácil. Incluso aquí sería interesante detenerse en las versiones distintas del acosador y el acosado respecto al primer encontronazo que dará origen a todo.

Cuando la violencia es pública (y en el reducido microcosmos de una clase todo se sabe), el resto de la masa se suele sumar a la violencia inicial. Una vez tirada la primera piedra es fácil alargar la mano para continuar soltando pedradas amparados en el anonimato de la masa homogénea. No hace falta tirar piedras: a menudo basta la pasividad para ser parte de la masa anónima que condena a la víctima inocente sobre la que recae la ira acumulada. En el fenómeno del bullying quizá la violencia de la masa no sea tan evidente, pero los medios de comunicación ya nos han acostumbrado a pensar que quien calla es cómplice (participante) del acoso y la violencia (Montero, 2013).

Está claro que el fenómeno del bullying se da cuando la masa homogénea que constituye una clase lo consiente: el acosador al fin y al cabo es el que tira la primera piedra (la más difícil de arrojar, por cierto), el resto se va sumando a la violencia colectiva por el efecto que Girard llama en ocasiones «bola de nieve» (Moreno, 2013, pp. 199-200; Girard, 2006, p. 22). Importa poco cuál fue el detonante de la violencia desatada contra el chivo: la bola va creciendo y su velocidad aumentando exponencialmente según pasa el tiempo; al final la distribución de responsabilidades en un fenómeno de bullying afecta a gran parte de la clase, cuando no a toda. De esto queda hoy constancia gracias al registro físico de los mensajes de 
texto en las redes sociales: atribuir la exclusiva responsabilidad de un mensaje vejatorio a su autor es desconocer la tremenda seguridad que da actuar amparado por el «anonimato» de una espiral violenta y creciente.

¿Qué determina que alguien sea elegido como víctima? Según Girard es imposible saber a priori quién se convertirá en víctima. Sin embargo, sí que hay algunas constantes o rasgos victimarios (Girard, 1986, p. 21) que permiten predecir quién es más proclive a convertirse en chivo. Lo más interesante que dice Girard al respecto es que la mayor probabilidad de convertirse en víctima inocente recae precisamente en los más débiles de la cadena. La masa elige a la víctima que no se va a poder defender por sí misma de los golpes que le van a llover; no se elige al «fuerte» (en sentido físico pero sobre todo psicológico), al bien posicionado, al bien relacionado.

Además de esto, existen incluso algunos rasgos físicos que aparecen en los chivos expiatorios. En las persecuciones medievales de los judíos eran sus características físicas, como el olor, la forma de vestir, etc. Si entendemos que la cacería de brujas que se desató en Europa en los siglos xvı y xvII era un fenómeno similar, también encontraremos detalles físicos que indicaban la marca del chivo (Harris, 1980). En los institutos de secundaria el chivo expiatorio puede ser un niño bajito o enclenque, miope o de orejas grandes, etc. Los ejemplos son abundantes, incluso en los relatos literarios este esquema se repite de modo inconsciente. En la reciente novela de Joël Dicker, El libro de los Baltimore, esto ha sido inconscientemente resaltado: «pues en el colegio, eso de ser tan menudo, lo había convertido en el chivo expiatorio habitual de los otros alumnos» (Dicker, 2015, p. 705).

En los fenómenos de chivo expiatorio suele haber una marca física que justifica incluso la violencia desatada contra la pobre víctima. El defecto físico se asocia con el defecto moral. Aparece así el discurso victimizador, que convierte al inocente en víctima sobre la cual puedo descargar mi ira porque es efectivamente culpable.

\subsection{Sacrificio del chivo expiatorio, el frenazo de la violencia y el comienzo de la mitología}

En la teoría de Girard el chivo expiatorio tiene dos salidas posibles, como los de la Biblia: la muerte o la expulsión de la comunidad. El chivo expiatorio puede acabar con la muerte, porque en el fondo es lo que se desea desde el principio: el deseo de suprimir al otro que ejercía de mediador del deseo (de suprimirnos los unos a los otros) se ha canalizado hacia una única víctima (Moreno, 2013, p. 198). Y la muerte es desgraciadamente real, sea por el impacto de las piedras de la masa amorfa, sea porque la única salida que ha vislumbrado el chivo a su situación es la de cometer suicidio. En otras ocasiones la violencia se resuelve con la expulsión de la víctima, lo cual no deja de ser una muerte simbólica. La víctima ha de cambiar de lugar de residencia, de país o de colegio. Aun en el caso en que sea por propia voluntad, es evidente que lo hace forzado por haberse situado en el centro de una conjura silenciosa que lo ha convertido en el imán de las violencias largamente reprimidas. De nuevo, de modo inconsciente, en la novela de Dicker: «... los demás niños se metían tanto con él que en dos años lo cambiaron de colegio tres veces. Pero en todas ellas acabó siendo tan desgraciado en el nuevo centro como en los anteriores» (Dicker, 2015, p. 750). Si en el caso 
de que se produzca suicidio a nadie se le ocurre justificar la acción diciendo: «Es lo que él ha querido", tampoco deberíamos desentendernos del que se cambia de colegio porque «es su decisión».

Pero he aquí que cuando la víctima muere, real o simbólicamente, sucede algo inesperado: la violencia se acaba, al menos por el momento. Impresionada por lo que acaba de suceder, la masa con las manos ensangrentadas deja de tirar piedras. Por un tiempo la violencia que llevó al sacrificio del chivo remite. Porque en la teoría de Girard, la muerte del chivo es un sacrificio sustitutorio de la violencia mimética, que ejerce como freno de dicha violencia. El frenazo de la violencia (Moreno, 2013, p. 200) hace que se atribuyan inmediatamente al chivo poderes mágicos y catárticos. Pero entonces tenemos que empezar a borrar las huellas de lo que hemos cometido, y tenemos que hacer creer al mundo que el chivo no era una víctima inocente, sino un malvado culpable que merecía el castigo. Es el inicio de la mitología, que en el fondo, según Girad, siempre esconde alguna víctima inocente que se nos intenta presentar como culpable (Girard, 2002, pp. 73-87; Millán, 2008, pp. 63 y ss.); exactamente como hacían los perseguidores de los judíos en la Edad Media (Girard, 1986, pp. 7-20).

De un modo análogo, también en un instituto se frena la violencia una vez que la víctima ha muerto, real o simbólicamente. Durante un buen tiempo el fenómeno no se repetirá. Y también aparecerán los relatos justificadores ex post facto: en el fondo se lo merecía, se lo había buscado, era su culpa, no supo hacer frente a la situación, estaba desequilibrado, no encaja en la sociedad, etc. Relato victimizador que encuentra toda su justificación en el hecho de que la muerte de la víctima realmente ha traído la paz: estamos más tranquilos. Hemos interiorizado tanto el esquema que hasta es posible encontrarlo en el cine (López, 2012).

Y sin embargo la muerte del chivo, indica Girard, provoca una falsa paz. Porque seguimos siendo humanos, deseando a través de los ojos del otro e intentando diferenciarnos mientras nos homogeneizamos más. Y se vuelve a generar la violencia que no había sido frenada en sus causas profundas, sino solo en la epidermis. En el fondo, la masa homogénea es cobarde e ineficiente porque repetirá las mismas violencias institucionalizando la violencia a través de la religión (Girard, 2012) mientras no se decida a reconocer lo único que ha conducido a la muerte del chivo: su propia culpabilidad. Según Girard, Jesucristo desde la cruz ha desvelado de una vez por todas (para quienes lo quieran ver) el mecanismo victimario que engrasaba las ruedas de la sociedad (Girard, 2002, pp. 37-52). El mero hecho de ser capaz de reconocer el fenómeno del chivo expiatorio ya es un paso de gigante: llamar a alguien chivo expiatorio es reconocer a la par su inocencia y la injusticia cometida con él.

\section{La teoría de René Girard evidenciada en algunas causas JUDICIALES ESPAÑOLAS SOBRE BULLYING}

Para ahondar en estas aplicaciones de la teoría del chivo expiatorio al bullying hemos utilizado cinco sentencias de la Audiencia Provincial de Castellón (JUR\2017\108910; JUR\2015\225667;

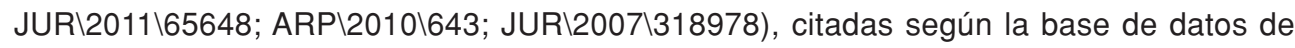
Aranzadi, y una de la Audiencia Provincial de Guipúzcoa (JUR\2005\174855), esta última por ser un triste referente en nuestra historia, al juzgar el caso de Jokin, un joven que se suicidó en 2004 en la localidad de Hondarribia. 
Aunque tomemos la clase como microcosmos, en muchos casos hay que considerar que la comunidad que sufre una perturbación es el propio centro educativo, pues los agresores y el agredido no siempre pertenecen a la misma clase, aunque siempre al mismo instituto. Hay que tener en cuenta, además, que los alumnos de institutos públicos no coinciden siempre en la misma clase, pues cambian de compañeros en función de las asignaturas de las que están matriculados. Por otro lado, esto no significa que la agresión permanezca en el instituto, pues muy a menudo se extiende al exterior del centro; así, en el caso de Jokin, los hechos que desencadenan el acoso tienen lugar fuera del instituto, y el acoso se desarrolla tanto fuera como dentro del centro por todo el grupo de amigos (JUR\2005\174855). En otro caso, los padres de una víctima de acoso denunciaron que habían sufrido desperfectos en el rellano de su vivienda, en el contexto de este acoso (JUR\2007\318978).

La hipótesis de la que partimos, y que será objeto de análisis más detallado en posteriores trabajos, es que la agresión, potencial o real, se inicia desde primer curso de la ESO, lo que significaría que la perturbación de la comunidad existe en el origen mismo del miedo a enfrentarse a una situación desconocida (pasan de ser los reyes del colegio a ser los últimos del instituto). Por ello temen ser elegidos como objeto de burlas y maltratos, temen ser elegidos chivos. Cuando reconocen entre ellos a uno aparentemente débil, lo señalan como chivo y fomentan que los demás hagan lo mismo.

Para esta aproximación, queremos centrarnos especialmente en la sentencia de la Audiencia provincial de Castellón de 10 de febrero de 2017 (JUR\2017\108910), no tanto por ser la más reciente de cuantas hemos analizado, sino por ser la que más se ajusta a la hipótesis de partida. Lo concretaremos en cinco ideas fundamentales.

\subsection{Primera}

Se trata del maltrato a un niño de $1 .^{\circ}$ de la ESO, por lo que encaja con la hipótesis formulada de que es en el primer curso cuando se señalan las víctimas. Según la sentencia, ofensor y ofendido coincidían en la clase de castellano. Pero también le insultaba y se burlaba de él «Cuando le veía, en cualquier ocasión», lo que reafirma la idea de que la comunidad perturbada es el instituto, y no solo el aula.

De los hechos que aparecen probados en otras sentencias, podemos afirmar que al menos en otro caso parece que la agresión también se inició en primero de ESO. Se trata de la agresión a otro alumno, del cual se afirma que era alumno de 2. de la ESO, pero al que ya el curso anterior dos alumnos lo habían incomodado y hostigado (ARP\20101643).

\subsection{Segunda}

La víctima tiene rasgos físicos que lo pueden identificar y que son usados para ser señalado como tal. En este caso se le acusa de tener cara de rata y de joker (malvado de Batman), por el aparato que llevaba en la boca que además le producía eccemas. También es señalado como «orejotas» (JUR\2017\108910). El niño llega a sentirse tan mal que cuando le volvieron a salir eccemas dejó de ir dos días a clase para evitar la humillación. 
A otro alumno, víctima de un caso al que ya nos hemos referido, se le acusaba de gordo (ARP $\backslash 20101643)$, mientras que en otro caso, con dos víctimas, uno era acusado de tapón, enano o retaco, y el otro de Dumbo, orejas grandes (JUR\2015\225667). Hasta tal punto que la víctima a la que se acusaba de orejas grandes decide someterse a una operación de cirugía estética.

Además de rasgos físicos, en muchos casos las víctimas tienen bienes materiales que son deseados por los acosadores, al menos en un momento inicial del acoso. Así, el teléfono móvil

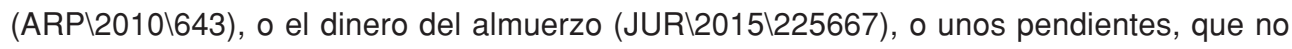
fueron devueltos a la acosada por parte de una de las acosadoras (JUR\2007\318978).

Junto a cualidades físicas o al deseo mimético de bienes, hemos detectado un tercer tipo de rasgos que identifican una víctima. Se trata de cualidades familiares, como ser huérfano de padre (JUR\2011\65648). Se burlaban de él afirmando que ellos al menos tenían padre, y el suyo estaba muerto, lo cual coincide con que la elección se ha producido sobre alguien más indefenso, o tener un hermano del que se dice que es homosexual (JUR\2015\225667); una de las expresiones que se utilizaban para referirse a esta víctima de acoso era la de «maricón».

\subsection{Tercera}

La violencia se inicia por un sujeto y se va extendiendo, primero por el círculo de imitadores y luego se generaliza a otros compañeros de clase o incluso del instituto. Este aspecto, la conversión del grupo en masa, y el contagio mimético de la violencia, es esencial para comprender cómo a través del grupo empiezan a liberarse del temor a ser señalado, y pasan a considerarse como fuertes, imitando al fuerte en apariencia, que se encara contra el débil al que acusa, y al que hace cargar con la culpa. Así, en la propia sentencia que estamos analizando, el juez afirma: «Esta situación convirtió a Edelmiro en víctima propicia de bromas y burlas por otros menores de 14 años como tirarle restos de rosquilletas de una bolsa en la cabeza, registrarle la mochila, beberse el agua, tirarle el bocadillo...» (JUR\2015\225667).

Siguiendo con la coincidencia terminológica, en muchas sentencias se considera probado que la víctima es acusada de chivato, bien directamente, bien indirectamente (JUR\2005\174855, JUR\2007\318978) — «¿tú que vas diciendo por ahí?»—, advirtiéndole de que si cuenta algo tendrá consecuencias (JUR\2017\108910 y JUR\2015\225667). Es al menos curioso que la víctima propicia de burlas e insultos sea un chivato, expresión evidentemente ligada al chivo. Parece, por tanto, que cuando se acusa a alguien de chivato, aunque sea inconscientemente, se le está situando frente a la comunidad como alguien que está rompiendo la confianza del grupo y rompiendo la paz, pues no es de fiar. Queda señalado con esta expresión, chivato, que indica tanto al delator cuanto al chivo expiatorio.

\subsection{Cuarta}

Aquellos de la masa que no pasan a ser agresores activos, se convierten en agresores pasivos, pues contemplan la violencia pero permanecen al margen y posiblemente justifiquen 
mentalmente su silencio y su pasividad. Encontramos el caso de un puñetazo en presencia del resto de alumnos (JUR\2015\225667) y además encontramos muchos casos en los que no hay compañeros que testifiquen contra los agresores. En ocasiones incluso el único testigo es exculpatorio (ARPI2010 643). Esto lleva al punto de que en dos de los casos el centro decidió aislar a la víctima del resto del alumnado (JUR\2011\65648 y JUR\2007\318978). En este último caso la alumna se pasaba el recreo en un aula con la psicóloga del centro.

\subsection{Quinta}

La víctima acaba siendo expulsada de la comunidad, al haberse visto obligada a cambiar de instituto, como se reconoce en la sentencia: «Como consecuencia de esta situación Edelmiro cambió de centro escolar al curso siguiente» (JURl2011|65648). Esto es una constante en la casi totalidad de los casos analizados. La situación se vuelve tan insostenible que la víctima es la que, de hecho, acaba fuera del centro. Según la teoría de Girard, tras la expulsión la paz se recupera.

Los cinco puntos que hemos constatado en las sentencias judiciales y que coinciden con la teoría de Girard son los siguientes: el momento de inicio coincide con una situación de inseguridad-insatisfacción generalizada; existen rasgos victimarios fácilmente reconocibles; junto al sujeto agresor se va conformando un círculo de imitadores porque la violencia se replica; el resto de la masa actúa pasivamente justificando lo que ocurre; por último, se produce la expulsión o muerte simbólica de la víctima.

El deseo mimético que Girard sitúa en la base de toda violencia tiene lugar, en nuestro caso, principalmente por el deseo que tienen los alumnos de los cursos iniciales de tener la seguridad de los alumnos de los cursos superiores. Este deseo de ser fuertes provoca la búsqueda a través de rasgos victimarios de personas débiles que van a ser utilizadas como chivos expiatorios, que van a generar una situación de superioridad en los agresores, que eliminará el miedo y me homologará al fuerte.

\section{La prevención del acoso escolar desde la filosofía de Girard}

Tras esta exposición sobre la doctrina de Girard aplicada al acoso escolar, debemos explorar necesariamente una serie de propuestas de carácter preventivo que podemos extraer también de los textos del filósofo francés. Es innegable que en la actualidad, antes de aplicar sanciones penales ejemplares, es fundamental acertar en la prevención, detección y finalización temprana de cualquier situación de violencia escolar. ¿Cuáles son las claves en las enseñanzas de Girard?

El mundo que nos rodea es un mundo global y posmoderno, lo que implica por un lado el acercamiento entre todos los seres humanos y un cambio importante en las creencias de estos. Por una parte, lo primero provoca que al estar todos más cerca se intensifiquen los deseos de que al parecer todo es posible de adquirir, ya que la reciprocidad es más intensa, las diferencias sociales se reducen y las normas culturales que marcaban distancias entre los ciudadanos parece que han perdido vitalidad (Bauman, 2002). Todo ello genera una sociedad 
donde la violencia puede arraigar con facilidad al estar presidida por la indiferenciación. Esta sociedad de masas tienen un componente cuantitativo, todos estamos más cerca, pero también uno cualitativo, un cambio global también de las creencias que Ortega y Gasset calificaría como una crisis moral (Ortega y Gasset, 1983, p. 172). Dicha decadencia moral se debe al imperio de la utilidad, de la inmediatez y especialmente del culto a un supuesto proyecto personal en el que la diversión y el placer son los principales objetivos. Estos dos rasgos de la sociedad actual no solo determinan cómo se da hoy el fenómeno de los chivos expiatorios sino que desvelan también las vías para una posible solución. Si la cultura posmoderna parece no ser la más adecuada para poder atajar el acoso escolar, ¿qué debería caracterizar a una cultura que sí lo hiciese?

Desde la perspectiva de Girard nos hallamos ante una vida humana falsificada, una mentira romántica que nos lleva a pensar que la competitividad y la violencia por lograr un ideal o proyecto personal es el único objetivo de nuestra existencia, proyecto que solo puede sostenerse recurriendo a más deseo y más violencia, por lo que se convierte en un sistema perverso o incluso satánico. En otros contextos históricos tenían sus propias armas para explicar a los jóvenes en qué consiste la vida real, tal es el caso, por ejemplo, de los ritos de paso. Estos servían para adentrar al joven en la madurez, intentaban mostrarle la dureza de la vida adulta, haciéndoles vivir una experiencia significativa que quedaba grabada para el resto de sus vidas. Como dice Girard en La violencia y lo sagrado: «los ritos de paso conceden a los neófitos un sabor anticipado de lo que les aguarda si transgreden las prohibiciones, si descuidan los ritos y se desvían de lo religioso» (Girard, 1995b, p. 305). Hoy, sin embargo, en nuestra sociedad no existen los ritos de paso, al menos en este sentido, y si existen no son más que exaltaciones de la diversión y de la libertad que hacen sentir al joven más poderoso que nunca y capaz de llevar a cabo todos sus proyectos personales por encima de quien haga falta, en definitiva más que una prevención resultan un aliento. Es necesario desmontar la mentira romántica y para ello se necesitan experiencias significativas. No es simplemente una cuestión de enseñar sino de vivir, no es suficiente una charla sobre las consecuencias del acoso en el colegio, es necesario que sientan las consecuencias de cualquier tipo de violencia y lo hagan de cerca.

En opinión de Girard la solución al problema de la violencia pasa por el reconocimiento de la culpabilidad de aquel que la ejerce (yo incluido) (Barahona, 2014, pp. 185-187). En este sentido, ampliar la solución al reconocimiento de la tentación de ser violento sería un paso para prevenir la violencia. Para ello es fundamental una educación que permita a la persona reconocer la tentación de ser violento, sus causas y el proceso de direccionamiento de dicha violencia. Teniendo todo esto en consideración, podría hacerse una propuesta para atajar el acoso escolar desde la educación a partir de tres directrices y una propuesta global de sentido.

\subsection{Educar para superar las frustraciones}

El bullying y en general toda la violencia es el resultado de la gran decepción que supone no poder hacer realidad los deseos personales que imitamos de los demás. Ante esto, tendrá que desarrollarse entre los jóvenes una sólida educación para superar las frustraciones. «Los 
perseguidores siempre acaban por convencerse de que un pequeño número de individuos, o incluso uno solo, puede llegar, pese a su debilidad relativa a ser extremadamente nocivo para el conjunto de la sociedad» (Girard, 1986, p. 25). Los acosadores culpan siempre a un chivo por la situación que viven y que en verdad no hace más que ocultar el verdadero fracaso, que consiste en no conseguir los fines propuestos. Se necesita pues educar a los niños desde pequeños en cómo reconocer y superar las frustraciones; esto limitará el bullying en el futuro.

\subsection{Hacer una adecuada pedagogía de la vulnerabilidad con los jóvenes}

La pedagogía de la frustración debe acompañarse con una pedagogía de la vulnerabilidad. A propósito de las violencias provocadas por el deseo mimético afirma Girard: «La diferencia al margen del sistema aterroriza porque sugiere la verdad del sistema, su relatividad, su fragilidad, su fenecimiento» (Girard, 1986, p. 33). Las diferencias que son manifiestas en nuestra sociedad muestran una serie de fortalezas, pero especialmente muestran la debilidad y la vulnerabilidad de las personas. Ahora bien, no parece que los violentos estén dispuestos a reconocer sus debilidades y ello provoca sus violentas reacciones ante todos aquellos que se atreven a poner en duda las pocas convicciones que tienen.

Cuando Girard habla de que el chivo en el fondo lo es porque produce algún tipo de efecto terrorífico en el grupo, está claro que lo hace porque este descubre la debilidad de la naturaleza humana, sus imperfecciones, su vulnerabilidad. Los defectos personales que culpabilizan al chivo son, en realidad, monstruosidades en potencia de todos los miembros que, en lugar de afrontarlas y descubrir sus implicaciones, los violentos optan por eliminarlas y encubrirlas para no dañar la imagen falsa que se crean de sí mismos.

Educar en la vulnerabilidad, en la fragilidad humana y en el fondo en la humildad parece importantísimo para el futuro de la educación respecto a la prevención del bullying.

\subsection{Educar con más historia y con mejor historia}

La historia es el gran testimonio de las grandes violencias de la humanidad. El estudio de la historia, de sus personajes, acontecimientos e interpretaciones es un libro abierto que desvela la naturaleza humana, sus errores y aciertos. Los mitos y los sucesos pasados nos hablan de nosotros mismos y no podemos olvidarnos de sus repercusiones. La historia está cargada de violencia cuyo conocimiento profundo puede ser también un antídoto para el bullying en los tiempos que corren, porque su conocimiento provoca una sensibilidad social auténtica. El desprestigio y la poca importancia que hoy se le da a la historia, y a las humanidades en general, en la educación secundaria sin duda favorecen la existencia de más casos de acoso escolar. Como ha expresado Díaz Leguizamón: «Un mayor conocimiento histórico permitiría así poder elaborar la violencia, dirigiéndola por canales que resulten productivos y benéficos, pero eso solo se lograría transitando por una autocomprensión del mecanismo mimético de nuestros propios deseos» (Díaz, 2010, p. 90).

Más y mejor enseñanza de la historia equivale en definitiva a prevención de la violencia en general y del acoso escolar en particular. 


\subsection{Ante la deshumanización del bullying necesitamos más humanización, más cristianismo}

Es bien conocida la gran apuesta que Girard hace por el cristianismo ante la violencia de nuestras sociedades (Scubla, 1988, pp. 160 y ss.). No es de extrañar que en un contexto donde el cristianismo está siendo apartado de la educación, las violencias afloren con intensidad. Cristo ha revelado cuál es la naturaleza de la violencia y ha mostrado la inutilidad de la misma en todas sus vertientes, especialmente en la del chivo expiatorio. Con su muerte como inocente pone en evidencia todo un sistema fallido de comprensión de uno mismo y de la realidad, a la vez que abre una vía para que dicho sistema se vaya resquebrajando. El vino nuevo de Jesús ha provocado que los odres de la vieja cultura de la violencia comiencen a reventarse. La propuesta de Jesús es que las personas dirijamos hacia él nuestro deseo mimético y por ello él mismo se propone como modelo (Llano, 2004, p. 99): en el centro de este modelo está el mandato divino de amar a Dios sobre todo y al prójimo como a uno mismo hasta el extremo de dar la vida. Ante el deseo desbordado que marca la sociedad actual y los sacrificios a los que aboca, resuenan las palabras de Jesús: «Aprended de mí que soy manso y humilde de corazón» (Mt. 11, 29).

En este contexto introduce Girard la idea de «colaboración negativa» (Girard, 2006, p. 32), que consiste en responder a las violencias con más violencia, lo que provoca entonces la legalidad de la continua violencia como respuesta. Este suceso aparece en cualquier momento, pero Jesucristo nos invita a frenarlo. Los chivos expiatorios que no responden violentamente a la violencia pueden provocar con esta actitud la vergüenza moral del agresor. Pensemos en Jesús o en tantos ejemplos de oposición no violenta que pueden estudiarse en la historia. El mal no encuentra así justificación, se muestra tal cual es. En el bullying, habitualmente los violentos quieren exasperar a la víctima para que reaccione y así poder decir que es en defensa propia, de forma que la violencia que aplican quede de alguna forma justificada. Ante ello destaca la imagen de Jesús callado ante sus verdugos: esa es la clave. Si los chivos reproducen la actitud de Jesús, el mal queda desenmascarado. Dice Girard:

Estos malvados no desean nada tanto como exasperarnos, para arrastrarnos con ellos a un proceso de escalada violenta. Hacen todo lo posible, en el fondo, para suscitar represalias que justificarían que después dieran rienda suelta a su enfado. [...] Es necesario privarlos de la colaboración negativa que reclaman de nosotros. (Girard, 2006, pp. 33-34)

Como dice san Pablo y recuerda Girard: «renunciar a las represalias es echar ascuas sobre la cabeza del adversario, dicho de otra manera, es poner a este último en una situación moral imposible» (ibid.).

\section{Conclusión}

En este artículo hemos visto los pasos que, según Girard, conducen desde la violencia mimética en la que se ve envuelta la sociedad en general o el aula de un colegio, hasta el 
frenazo de la violencia producido por la muerte simbólica de una víctima inocente que ha atraído sobre sí la animadversión de la masa. La teoría de Girard ha sido verificada en distintas causas judiciales reales que se ajustan bien a los pasos sugeridos por él. Queda así demostrada la potencia analítica de la propuesta girardiana. Por último, hemos esbozado algunas propuestas de solución que se desprenderían del propio Girard, y que podrían servir para detener el incremento de violencia: educar para la frustración y la vulnerabilidad, aumentar el conocimiento de la historia y estar dispuestos a reconocer nuestra propia participación en violencias colectivas.

\section{Bibliografía}

Ballesteros, B. (2018). III Estudio sobre Acoso escolar y ciberbullying. Madrid: Fundación Mutua Madrileña y ANAR. Recuperado de https://www.anar.org/wp-content/uploads/ 2018/09/III-Estudio-sobre-acoso-escolar-y-ciberbullying-seg\%C3\%BAn-los-afectados.pdf (consultado el 25/07/2019).

Barahona, A. (2001). «La violencia escolar», Acontecimiento, n. 58, pp. 37-42.

- (2014). René Girard. De la ciencia a la fe. Madrid: Encuentro.

Bauman, Z. (2002). Modernidad líquida. Buenos Aires: FCE.

Biagioli, N. y Martínez, M. L. (2006). «Harry Potter: de la crisis de las diferencias a la diferenciación de las identidades y de las disciplinas (una aproximación antropológica de la

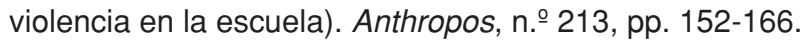

Burbano, M. (2010). «La teoría mimética de René Girard y su aporte para la comprensión de la migración». Universitas Philosophica, n. 55, año 27, pp. 159-181.

De Vaux, R. (1076). Instituciones del Antiguo Testamento. Barcelona: Herder.

Díaz, J. M. (2010). «Elementos para la reconstrucción de una filosofía de la historia en René Girard», Universitas Philosóphica, n. 55, año 27, pp. 75-91.

Dicker, J. (2015). El libro de los Baltimore. Madrid: Alfaguara (edición Kindle).

Douglas, M. (1978). Natural Symbols. Middlesex-England: Penguin Books.

Dumouchel, P. (ed.) (1988). Violence and Truth. On the work of René Girard. Londres: The Athlon Press.

Eichrodt, W. (1975). Teología del Antiguo Testamento. Dios y pueblo. Vol. 1. Madrid: Cristiandad.

García-Durán, X. (2012). «René Girard: una aproximació desde Mensogne romantique et vérité romanesque a Achever Clausevitz». Comprendre, 14/2, pp. 71-84.

Girard, R. (1986). El chivo expiatorio. Barcelona: Anagrama.

- (1985). Mentira romántica y verdad novelesca. Barcelona: Anagrama.

- (1995). Shakespeare. Los fuegos de la envidia. Barcelona: Anagrama.

- (1995b). La violencia y lo sagrado. Barcelona: Anagrama.

- (1996). Cuando empiecen a suceder estas cosas. Madrid: Encuentro.

- (2002). Veo a Satán caer como el relámpago. Barcelona: Anagrama.

- (2006). Aquel por el que llega el escándalo. Madrid: Caparros.

- (2009). La anorexia y el deseo mimético. Barcelona: Marbot ediciones.

- (2012). El sacrificio. Madrid: Encuentro. 
Harris, M. (1980). Vacas, cerdos, guerras y brujas. Los enigmas de la cultura. Madrid: Alianza.

Llano, A. (2004). Deseo, violencia, sacrificio. El secreto del mito según René Girard. Pamplona: Eúnsa.

López, J. J. (2012). Cine y teoría del chivo expiatorio. Aproximaciones a la teoría del chivo expiatorio en los juicios penales a través de cuatro producciones cinematográficas. (Tesina de especialización en filosofía del derecho. Universidad Libre de Colombia). Recuperado de: http://repository.unilibre.edu.co/bitstream/handle/10901/7497/LopezQuitianJohanJavier.pdf;sequence=1 (consultado el 3/1/2018).

Maurel, O. (2006). «El respeto a los niños, una vía hacia la autonomía al margen del mimetismo de la violencia». Anthropos, n.ำ 213, pp. 141-151.

Mardones, J. M. (2006). «Religión, cultura y violencia: la teoría mimética de R. Girard».

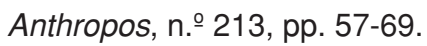

Martínez, M. L. (2006). «Aproximación antropológica a la violencia en la escuela y en el deporte». Anthropos, n.ำ 213, pp.167-193.

Millán, J. A. (2008). «Los mitos según René Girard». Amaltea: revista de mitocrítica, n.ํㅜㅇ, pp. 63-86.

Moreno, A. (2013). «Descripción y fases del mecanismo del chivo expiatorio en la teoría mimética de René Girard», Endoxa, UNED, n.ํ32, pp. 191-206.

Montero, M. (dir.) (2013). «La cadena del silencio», del programa Crónicas, emitido en RTVE el 11 de abril de 2013. http://www.rtve.es/alacarta/videos/cronicas/cronicas-cadena-del-silencio/1760607/ (consultado el 2/12/2017).

OECD (2015). PISA Results. Vol. III. Student's Well being. Recuperado de https://www. oecd.org/education/pisa-2015-results-volume-iii-9789264273856-en.htm (consultado el 25/07/2019).

Oñate, A., y Piñuel, I. (2007). Acoso y violencia escolar en España. Informe Cisneros X. Instituto de Innovación Educativa y Desarrollo Directivo.

Ortega y Gasset, J. (1983). La rebelión de las masas. Barcelona: Orbis.

Piñuel, I. (2001). Mobbing: cómo sobrevivir al acoso psicológico en el trabajo. Santander:

Sal Terrae.

Piñuel, I., Cortijo, O. (2016). Cómo prevenir el acoso escolar. La implantación de protocolos antibullying en los centros escolares: una visión práctica y aplicada. Madrid: CEU Ediciones.

PISA, Informe recuperado de https://www.oecd.org/pisa/Well-being-Infographics.pdf (consultado el 25/07/2019).

Scubla, L. (1988). «The Christianity of René Girard and the Nature of Religion», en Dumouchel, P. (ed.) (1988). Violence and Truth. On the work of René Girard. Londres: The Athlon Press, pp. 160-178.

Slater, P. E. (1966). Microcosm. Structural, psychological and religious evolution in groups. USA: Library of Congress.

VVAA. (2006). «René Girard. Deseo mimético y estructura antropológica». Anthropos, n.은. 213. Vilarrasa, D. (2008). «El aula es un microcosmos». Aula de innovación educativa, Graó, n.․ 173-174, pp. 59-60. 